\title{
HOLIDAY BRUCELLOSIS
}

Colonel E. E. VELLA, M.D., M.I.Biol., F.R.C.Path., Late R.A.M.C.

Mr. D. GOODE, F.I.M.L.T., L.I.Biol.

Royal Army Medical College, Millbank

SUMMARY: A case of Brucellosis melitensis infection in a Service family occurring after a summer holiday in the Mediterranean is described. This is the first human isolation of $\mathrm{Br}$. melitensis biotype 2 recorded from the island of Malta.

\section{Introduction}

During comparatively recent times we have been introduced to the new term Holiday Typhoid, and even more recently we have been compelled to think of Holiday Cholera. We would like to add a final third to complete the triad and coin the new phrase Holiday Brucellosis.

"Where have you been, and when?". In these days of fast, easy and cheap international and intercontinental communications, when travel by jet planes is so fast that passengers arrive at their destination in a time within the incubation period of the infectious diseases, this question hammered home so often by Maegraith should always be included in the preliminary case history taking of every patient, including young children, and especially young children from services' families, many of whom are seasoned travellers to an astonishing degree (Maegraith 1968).

This paper presents the history of a child (A) who went to Malta, together with other members of her family in the summer of 1969-the summer months are hot and dry in the Mediterranean, and Malta is no exception. Therefore, air (dust) borne infections are possible, in addition mosquitoes and sandflies are very numerous in small out-of-way villages. The family stayed in such a village, where dust and insects abounded: there has been, of course, no malaria in the Maltese Archipelago for many decades, but Leishmaniasis still occurs.

\section{Clinical history and findings}

The family consisted of the parents and three children aged respectively 17 years (E), 14 years (F) and 9 years (A). Towards the end of their holiday one child (F) complained of listlessness and apathy and would spend the day lying down, preferring to stay indoors, a most unusual behaviour for a school girl on her summer holidays. She also complained of a slight sore throat, slight hoarseness and a mild non-productive cough. The family returned to the United Kingdom in the first week of September and the children dispersed to their respective boarding schools. In the third week of September the youngest child (A) complained of headaches usually in the afternoon, while at other times feeling more or less quite normal. She was put to bed in the school's infirmary for a few days when it was observed that she was running a slight but continuous fever reaching to just above the $100^{\circ} \mathrm{F}$ mark, the highest point reached on one occasion was $100.2^{\circ} \mathrm{F}$. Apart from the fever and slight to moderate occipital headaches the only other symptom complained of was pain in the back and ankles on one occasion; physical signs were conspicuous by their absence. She was brought home from school and kept under observation for a few days, in the hope that the affection was either the tail end 
of some mild short-term viral fever or else that given time further signs and symptoms might unfold themselves and lead to a firm diagnosis, and consequent rational treatment. An awareness of brucellosis (mostly because of the nationality of the parents) existed right from the start, and as the child remained in status quo the clinical suspicion of Malta Fever was now well to the fore.

Accordingly two measures were instituted:-

a. Blood was taken for blood cultures, for serology and for a total and differential white blood cell counts.

b. The patient was placed on the newly marketed drug "Septrin" (one adult tablet a day) for 17 days; tetracycline ( $250 \mathrm{mg}$ q.i.d.) was added on the 14 th day to the Septrin regime, and continued for 21 days.

At the end of this course of treatment the child appeared to be more alert, had a good appetite but subjectively still complained of occasional headaches which had become of shorter duration and occurred either in late morning or early afternoon, so that by evening the child would appear and feel perfectly normal and well.

Two months after her initial symptoms the child was able to return to her boarding school where she stated that she was not quite readily off the mark as before; and did not assimilate new knowledge as well as before the illness.

\section{Special investigations}

a. Haematology. $\mathrm{Hb}-13 \mathrm{~g} / 100 \mathrm{ml}$. P.C.V. -39 per cent. W.B.C. $-5500 \mathrm{~mm}^{3}$. Polymorphs -2530 (46 per cent). Lymphocytes- 2310 (42 per cent).

b. Blood culture. Blood was taken from the patient and delivered directly into a serum-dextrose biphasic medium (Castaneda 1947). A growth was obtained on the 15 th day. The isolated organism had the morphological, cultural and biochemical properties of Br. melitensis, it was not lysed by Tbilisi phage. The organism was sensitive to the usual antibiotics (tetracycline, streptomycin, chloramphenicol). It was very sensitive to Septrin, partially sensitive to sulphamethoxazole and resistant to Trimethoprim. Synergistic action of the combined drug (Septrin-5 sulphamethoxazole and trimethoprim) was very marked.

c. Blood culture on Novy-Nicolle-McNeal (N.N.N.) medium for Leishmanial organisms proved negative.

d. Serology. Paired sera were tested as recommended by Kerr et al (1968) namely, standard saline agglutination, mercapto-ethanol agglutination, complement fixation and anti-human globulin (Coombs) test for incomplete antibodies; in view of the importance of sero-diagnosis in brucellosis, sera were also referred to another laboratory. Serum was also tested for leishmanial antibodies with negative results.

Results of the various tests-Paul Bunnell test, Widal test, Weil Felix test, Leishmaniasis C.F.T. and Brucella in Laboratory 2 were negative. Results of Brucella tests in Laboratory 1 are shown in Table 1.

e. Radiography. Nothing abnormal was detected in the roentgenograms of the chest and skull. 
Table I

Results of Brucella tests in Laboratory 1

\begin{tabular}{l|l|r|r|r}
\hline \multicolumn{1}{c|}{ Test } & Genus & Specimen 1 & Specimen 2 \\
\hline Saline test & $\begin{array}{l}\text { Br.melitensis } \\
\text { Br.abortus } \\
\text { Br.melitensis } \\
\text { 2-mercapto-ethanol }\end{array}$ & 80 & 80 \\
Br.abortus \\
Complement-fixation test \\
Br.melitensis \\
Coombs test
\end{tabular}

\section{Discussion}

Clinical findings. Brucellosis has protean manifestations-it is indeed a great mimic disease: It is probable that many patients remain incorrectly diagnosed for lack of awareness of the many ways in which this infection may present.

Matthew Louis Hughes (1897) entitled his classical monograph on this disease as Mediterranean, Malta or Undulant Fever, but one must not await, or indeed expect, the development of the classical " Undulant Fever "type of pyrexia before a diaghosis of Brucellosis is entertained, otherwise many a patient will be misdiagnosed or even remain undiagnosed.

Patient (A) had a fever which was a mild continuous fever averaging just below $100^{\circ} \mathrm{F}$ (reaching $100.2^{\circ} \mathrm{F}$ on one occasion only) very aptly described by the Maltese vernacular appellation for this infection, namely " deni irqiq" that is to say low-grade minimal fever. The cause of such a persistent fever in the patient is not necessarily to be correlated with a continuous state of bacteraemia (Ganado and Bannister 1960), but perhaps rather to be ascribed to the ingestion and destruction of the bacilli by the body's defensive cellular system, with consequent liberation of a leucocyte pyrogen (Cooper 1969), which would account not only for the pyrexia but for the headaches as well. The absence of physical signs especially of splenic enlargement which one almost instinctively looks for and expects to find in a bacteraemic disease like brucellosis should not deter the attendant physician from harbouring a suspicion of the disease. Splenomegaly like the fever may show itself to be a very irregular feature in this disease.

Laboratory diagnosis. Brucellosis may be diagnosed by the following laboratory procedures: -

a. Fluorescent antibody techniques (Biegeleisen, Bradshaw and Moody 1962, Edwards et al 1970). We have had no experience with FAT as applied to diagnosis of patients suffering from brucellosis, hence this was not attempted.

b. The isolation of the organism itself is of course definitive diagnostic procedure in this infection: Brucella organisms are slow growing and cultures must be kept for six weeks before discarding them as negative. It is stressed that blood cultures should be repeated many: times, and moreover it is not essential, nor indeed necessary, to withdraw blood only at the height of a pyrexial episode. Fortunately for our patient, blood culture 
proved positive at the very first attempt. This may well be due to the species isolated; $B r$. melitensis is considered to be more infectious and more virulent than Br. abortus (Agius 1965), on the other hand it is thought to be the easier micro-organism to isolate and culture in vitro. Castaneda's technique of using a diphasic liquid/solid culture medium is most convenient and has much to recommend it from the laboratory point of view.

Attempts at culturing the urine were not done. This was a grave omission and a regrettable confession to make. Observations that brucella organisms are excreted in the urine had been made many years ago by Major William Horrocks and Captain James Kennedy, members of the Mediterranean Fever Commission (Horrocks 1905) investigating this disease in Malta, and a search for these organisms in urine is recommended by W.H.O. (1964).

Having identified the organism isolated from our patient as Br. melitensis, a subculture was referred to the nearest F.A.O./W.H.O. Brucellosis Centre at the Central Veterinary Laboratory of the Ministry of Agriculture, Fisheries and Food, for confirmation and further investigation: and it was reported as follows:- "We have examined the culture and confirm your findings that it is Br. melitensis-biotype 2, this is in keeping with the history of a visit abroad".

This report of the isolation of a biotype 2 from a patient after a summer holiday in the island of Malta is worth noting. Br. melitensis is not met with in the United Kingdom where Br. abortus is the aetiological agent of brucellosis; exactly the opposite situation obtains in Malta where Br. melitensis biotype 1 reigns supreme. As far as the authors are aware this is the first isolation of biotype 2 from a patient infected in Malta reported in literature. We are greatly indebted to the kindness of the Senior Public Health Laboratory Officer, Malta for the following (1969) statistical data:-

a. All human cases have been confirmed as Br. melitensis biotype 1. Br. abortus and $B r$. suis have not been isolated from human cases.

b. Br. abortus of cattle belong to biotype 1 and $3 ; B r$. melitensis from goats belong to biotype $1 "$.

The fact that this particular biotype 2 can occur in Malta is supported by the findings of Alton (1968) of the F.A.O. Brucellosis Laboratory who typed several hundreds of Br. melitensis, isolated in the field in the islands of Malta and Gozo. He observed "all were biotype 1 " except for a few isolations from one herd of goats that were biotype 2 ; the herd were also infected with biotype 1 and it seems possible that a mutation had occurred!

c. Serological tests. Agglutination tests and complement fixation tests are in practice the two most valuable methods for the diagnosis of this disease. One is proud to recall that the Army Medical Services scored another first in this field, as agglutination tests for the detection of brucellosis evolved originally in the Army Pathology Department at Netley (Wright and Smith 1897). Antibodies, capable of fixing complement, occur at a later stage in the disease process than agglutinins (Foz and Garriga 1964).

Two recently introduced tests are Indirect Haemogglutination (IHA) and Buffered Antigen (BAT). 
The results of our tests showing-A titre of 1 in 80 in saline agglutination; A marked reduction of titre in mercapto-ethanol to below detectable level; A negative Coombs' test, and a negative complement fixation test confirm the diagnosis that patient (A) was in the early acute phase of the disease, that is to say she was suffering from a recent infection quite consonant with the history as detailed in the opening paragraph of this paper.

Treatment. It was decided to use "Septrin", a newly introduced antibacterial drug. After 14 days treatment there was no remarkable response in the patient's condition. The patient was not worse but she was not noticeably and objectively better. It was therefore decided to add tetracycline to the regime. It is felt that possibly two (adult) tablets of Septrin a day are too low a dosage for use in Br. melitensis infection, which is usually more severe and more difficult to treat than $B r$. abortus infections; certainly in vitro sensitivity tests on the Br. melitensis isolated from our patient showed that this particular biotype was very sensitive to Septrin, and therefore this new drug was well worth trying in view of its ease of administration. Owing to lack of published literature on this point to act as a guide line, and as combinations of sulphonamides and tetracyclines had been tried in the past, the exhibition of tetracycline was obviously indicated. At the end of the treatment there appeared to be a definite improvement in the child's condition which has been maintained.

Patient (A) will be kept under close observation in order to detect any signs of relapse, immediately this occurs. In such an event it is proposed to give a 21 day course of Septrin and tetracycline, using 3 adult tablets of Septrin and $1 \mathrm{~g}$ of tetracycline daily. Patient (F) the other child, showed only listlessness and complained of respiratory symptoms; the former is almost universally found in brucellosis and the latter is not an uncommon symptom. This girl has apparently recovered completely without treatment - this may represent one more facet of this disease, which presents so much that is of interest to the Service medical officer, and more particularly to the R.A.M.C.

"As it was owing to the perseverance and acumen of an R.A.M.C. officer that the real cause of the fever was discovered, and its right to be considered as a specific disease, distinct from enteric, malaria, etc., demonstrated; and it is also due to the work of the former Professor and Assistant Professor of Pathology, that we possess the method of serum diagnosis, Mediterranean fever may be considered in a great degree as the special property (if I may use the term) of our Corps' (Allen 1904).

\section{Acknowledgements}

We thank the Adviser in Paediatrics, Lieutenant-Colonel H. A. J. Reay for his suggestion to place this case ' on record'. Miss Wilson of the Parasitology Department of the Royal Army Medical College for the leishmania blood culture report. Dr. Robertson of the Seaman's Hospital, Greenwich for the leishmania C.F.T. report. Dr. L. Spiteri the Senior Public Health Laboratory Officer, Malta for statistical data. Dr. Brinley-Morgan, Director of the W.H.O. Brucellosis Centre, Weybridge for confirmation and identification of the biotype of the isolated organism and Dr. Frisch and Dr. Fowle of the Wellcome Foundation and the Wellcome Research Laboratories for advice on treatment and supply of drag-sensitivity discs. 


\section{REFERENCES}

Aguis, E. (1965). Arch. Inst, Pasteur Tumis 42, 31.

Allen, S. G. (1904). J. roy. Army med. Cps. 2, 703.

Alton, G. G. (1968). St. Luke's Hospital Gazette, Malta, 111, 74.

Biegeleisen, J. Z., Bradshaw, B. R. and Moody, M. D. (1962). J. Immunol. 89, 109.

Castaneda, M. R. (1947). Proc. Soc. exp, Biol. (N.Y.) 64, 114.

CoOper, K. E. (1969). Brit. J. Hosp. Med, 1, 1069.

Edwards, Joan M.B., Tannahill, Agnes J. and Bradstreet C. M. Patricia (1970). J. Clin. Path. 23, 161.

Foz, A. and Garriga, S. (1954). Rev. Immunol. (Paris) 18, 288.

Ganado, W. and Bannister, W. (1960). Brit. med. J. i, 601.

Horrocks, W. H. (1905). On the Recovery of the Micrococcus Melitensis From the Urine, Faeces, and Sweat of Patients Suffering from Mediterranean Fever. Reports of the Mediterranean Fever Commission, Part 1. Harrison, London. P21.

Hughes, M. L. (1897). Mediterranean, Malta or Undulant Fever. MacMillan, London.

Kerr, W. R., McCaughley, W. J., Cochlan, Joyce D., Payne, P. J. H., Quaife, R. A., Robertson, L. and Farrel, I. D. (1968), J. Med. Microbiol. 1, 181.

Maegraith, B. G. (1968). J, roy. Coll. Gen. Practit. 16, Symposium.

W.H.O. (1964) Joint F.A.D.W.H.O. Expert Committee on Brucellosis. 4th Report. Wld. Hith. Org. techn. Rep. Ser. No. 289.

Wright, A E. and Smith, F. (1897). Lancet i, 656.

\section{Honorary Consultants}

To the Army

Doctor C. N. Oswald, T.D., M.D., B.Chir., F.R.C.P., M.R.C.S., as Honorary Consultant in Diseases of the Chest to the Army, with effect from 31 August 1972, in succession to Professor F. H. Scadding.

Professor C. I. Phillips, M.Sc., Ph.D., M.D., F.R.C.S., D.P.H., as Honorary Consultant Opthalmologist to the Army in Scotland, with effect from 12 June 1972, in succession to Professor G. I. Scott.

\section{To The Queen Alexandra Military Hospital}

Mr. G. Westbury, F.R.C.S., M.R.C.P., as Honorary Consultant in Neoplastic Surgery to The Queen Alexandra Military Hospital, with effect from 11 September 1972, in succession to Mr. E. Stanley-Lee. 